\title{
Estresse pós-privação de sono: análises morfométricas do fígado
}

\section{Stress caused by sleep deprival: liver morphometric analysis}

Marilia Capuço Oliveira ${ }^{1}$, Neide Aparecida Micelli Domingos ${ }^{1}$, Alex Tadeu Martins ${ }^{1}$, Reinaldo Azoubel ${ }^{1}$, Maria Cristina de Oliveira Santos Miyazaki ${ }^{1}$, Rodrigo Estevan Imperial ${ }^{2}$, Milton Dorival Pires ${ }^{1}$, Moacir Fernandes de Godoy ${ }^{1}$

${ }^{1}$ Faculdade de Medicina de São José do Rio Preto (FAMERP) - São José do Rio Preto (SP), Brasil.

${ }^{2}$ Fundação Faculdade Regional de Medicina de São José do Rio Preto (FUNFARME) - São José do Rio Preto (SP), Brasil.

DOI: http://dx.doi.org/10.7322/abcshs.v38i2.11

\section{RESUMO}

Objetivo: Avaliar o efeito da exposição ao estresse pós-privação de sono em características celulares e nucleares do fígado de ratos. Métodos: 16 ratos (Wistar) machos adultos (200-260 g) foram mantidos em ciclo de luz controlado recebendo dieta com quantidades usuais de sal e livre acesso àágua e alimento. Os animais foram divididos em dois grupos de oito animais (grupo experimental e grupo controle). Os animais permaneceram na mesma gaiola (dois de cada vez) durante sete dias e, após esse período, foram pesados e separados. O animal do grupo controle continuou na mesma gaiola e o animal do grupo experimental foi colocado em aparato de privação de sono. Após as 96 horas, os dois ratos foram pesados, anestesiados, sacrificados com dose excessiva de anestésico e os fígados foram retirados. Resultados: Não há diferença significante entre o grupo experimental e grupo controle em relação ao peso, embora haja diminuição de peso no grupo experimental. Nas análises cariométricas, houve diferença significante em relação ao diâmetro menor $(p=0,03)$ e volume $(p=0,04)$ do núcleo dos hepatócitos do grupo experimental. Nas análises esteriológicas, houve diferença significante do grupo experimental no núcleo (maior, $p=0,036$ ), do citoplasma (menor $p=0,009$ ) e outras estruturas (maior $p=0,008$ ). Conclusão: $O$ estresse parece contribuir para alteração na estrutura celular hepática.

Palavras-chave: estresse fisiológico; fígado; privação do sono; cariometria.

\begin{abstract}
Objective: To evaluate the effect of stress induced by sleep deprivation on nuclear and cellular features of rat liver. Methods: 16 adult male Wistar rats (200-260 g) in controlled light cycle received diet with customary salt quantity and free access to water and food. The animals were divided into two groups with 8 animals each (experimental group and control group). Animals stayed in the same box (two at a time) during seven days and after that period they were weighted e separated. The control group animal continued in the same box and the experimental group animal were transferred to a sleep deprivation apparatus. After the 96 hours the animals were sacrificed by an excessive anesthetic dose; animals were weighted and their liver extracted. Results: There was no significant difference between experimental and control group regarding weight, although there was a decrease of weight on the experiment group. Karyotipical analysis showed significant smaller diameter $(p=0.03)$ and volume $(p=0.044)$ of hepatocyte nuclei in experimental group. Stereological analyses showed significant differences in experimental group for nucleus (larger, $p=0.036$ ), cytoplasm (smaller, $p=0.009$ ) and other structures (larger, $p=0.008$ ). Conclusion: Stress seems to contribute to alteration of hepatic cell structure.
\end{abstract}

Keywords: stress, physiological; liver; sleep deprivation; karyometry.

Recebido em: 08/02/2012

Revisado em: 20/05/2013

Aprovado em: 12/06/2013

Trabalho realizado na Faculdade de Medicina de São José do Rio Preto (FAMERP) - São José do Rio Preto (SP), Brasil. 


\section{INTRODUÇÃO}

O estresse tem sido definido como uma reação com componentes físicos e psicológicos, causada por alterações psicofisiológicas que ocorrem quando a pessoa se confronta com uma situação que a irrite, amedronte, excite ou confunda, ou mesmo que a faça imensamente feliz ${ }^{1}$

Existe uma relação clara e bem documentada na literatura entre estresse, seja esse por meio de um estímulo físico ou psicológico, e a estimulação do eixo hipotálamo-hipófise-adrenal (HHA). Ao sentir um estressor, o hipotálamo libera o fator de liberação de corticotropina (CRH) que estimula a secreção hipofisária do hormônio adrenocorticotrópico (ACTH). O hipotálamo ativa também a medula adrenal. Essa, por sua vez, secreta glicocorticóides (o principal deles é o cortisol) e mineralocorticóides (como a aldosterona), que interagem com o DNA celular controlando a síntese protéica ${ }^{2,3}$.

O cortisol atua de uma maneira intensa sobre o metabolismo hepático, induzindo alterações metabólicas produzindo diversos efeitos no metabolismo corpóreo tais como: estímulo da gliconeogênese, elevação da concentração sanguínea de glicose, redução das proteínas celulares, aumento na concentração sanguínea de ácidos graxos livres, obesidade por excesso de cortisol, entre outros ${ }^{4}$.

Um dos principais efeitos do cortisol sobre o metabolismo é a redução dos depósitos proteicos em praticamente todas as células corporais, exceto no fígado. Existe um estado de redução da síntese de proteína e maior catabolismo destas no organismo, e um dos efeitos do cortisol é aumentar o transporte de aminoácidos, elemento fundamental à síntese proteica, para o interior das células hepáticas. Ainda, tal hormônio estimula a ativação da transcrição de DNA nos núcleos dos hepatócitos. Todo esse processo, portanto, leva a um aumento da síntese proteica hepática ${ }^{4}$.

Estudos têm demonstrado que a síndrome metabólica ${ }^{5-8}$ está associada ao aumento da morbimortalidade e que também está associada ao aumento do cortisol e intolerância a glicose.

Pesquisas têm demonstrado que a diminuição ou privação de sono, em humanos, envolvem alterações metabólicas, problemas na regulação do apetite e diminuição do dispêndio de energia, tornando-se fator de risco para o desenvolvimento de várias doenças tais como doenças cardiovasculares, obesidade, resistência a insulina, intolerância a glicose, dislipidemia e hipertensão e manifestações que alteram a regulação de energia ${ }^{5,9-14}$.

Em animais, o estresse pode ser provocado por privação de sono, que por sua vez, ativa o eixo hipotalâmico-pituitário-adrenal ${ }^{15}$. Assim, o objetivo é analisar se os animais submetidos ao estresse pós-privação de sono apresentam alterações no peso e alterações morfométricas no fígado.

\section{MÉTODOS}

Tipo de estudo: estudo do tipo experimental de pré e pós-teste com grupo controle.

Modelo de privação de sono: o animal (individualmente) é colocado em uma caixa de polipropileno $(60 \mathrm{~cm}$ de comprimento;
$45 \mathrm{~cm}$ de largura; $45 \mathrm{~cm}$ de altura) fechada com uma tampa em arame inox. Dentro da caixa há uma plataforma $(6,5 \mathrm{~cm}$ de diâmetro), na qual o animal é colocado. Coloca-se água na caixa até aproximadamente $1 \mathrm{~cm}$ da superfície da plataforma ${ }^{16,17}$. $\mathrm{O}$ animal tem livre acesso a água e alimento.

O projeto foi aprovado pela Comissão de Ética na Experimentação Animal (CEEA) da FAMERP - Protocolo $n^{\circ}$. 001-002975/2008.

Procedimento: foram empregados 16 ratos, do tipo Wistar, machos adultos, com peso entre 200 a 260 g, fornecidos pelo Biotério da FAMERP. Os animais foram mantidos com livre acesso a água e alimentação (Labina/Purina), ciclo de luz controlado (12 horas de claridade e 12 horas escuro) e temperatura média de $25^{\circ} \mathrm{C}$. As gaiolas foram higienizadas de dois em dois dias. Os animais foram divididos em dois grupos: oito animais formaram o GE - grupo experimental, e oito animais formaram o GC - grupo controle. O experimento ocorreu com dois animais de cada vez (a cada 11 dias, dois novos animais eram submetidos ao procedimento até se atingir o número total de animais).

Todos os animais (dois a dois) foram pesados e colocados na mesma gaiola, na qual permaneceram durante sete dias em repouso. Após esse período, os animais foram novamente pesados e separados. O animal do GC continuou na gaiola inicial e o animal do GE foi colocado em uma caixa experimental - Aparato de PSD - Privação de Sono Dessincronizado, para privação de sono durante 96 horas. Durante a fase de privação de sono, os ratos eram pesados diariamente. Após as 96 horas, os ratos de ambos os grupos foram anestesiados, pesados, sacrificados com dose excessiva de anestésico Tiopental Sódico, na concentração de $50 \mathrm{mg} / \mathrm{mL} / \mathrm{kg}$ e tiveram o fígado removido.

Após o processamento laboratorial do fígado, foi fixado (ALFAC - álcool a $80 \%$; formol a $10 \%$ e ácido acético glacial puro), realizado cortes de seis micrometros e corados pela Hematoxilina/Eosina (HE). Foram obtidas lâminas, que foram analisadas em microscópio óptico (Olympus BX.60) acoplado a um computador munido com sistema de análise de imagens (Image Pro Plus 6.1) com aumento final de 100 vezes. Para a cariometria, foram determinados os eixos maior e menor de 50 núcleos de hepatócitos. Os dados obtidos permitiram a determinação dos seguintes parâmetros: diâmetros maior, menor e médio, relação entre os diâmetros maior e menor, área, volume, perímetro, relação entre o volume e a área, excentricidade, índice de contorno e coeficiente de forma.

Em relação à estereologia, o material foi submetido a áreas-testes preenchidas com 130 pontos pré-determinados em cada. Foram quantificados 20 campos estereológicos do fígado dos animais, obtendo 2.600 pontos para cada um. A determinação da densidade de volume das estruturas em análise baseou-se nos princípios de Weibel (1969), cujo volume relativo (\%) das estruturas em análise foi calculado através da fórmula: $P p i=P i / P(\mathrm{Ppi}=$ densidade de volume das estruturas das áreas, $\mathrm{Pi}=$ soma do número de pontos coincidentes sobre cada estrutura e $\mathrm{P}=$ número total de pontos do retículo, 
multiplicando-se o número de pontos do retículo pelo número de campos examinados).

Para análise estatística foram utilizados: Teste $t$ de Student e Mann-Whitney, sendo considerado significativo $p \leq 0,05$.

\section{RESULTADOS}

A Tabela 1 apresenta os resultados da variável peso obtidos na fase pré e pós-privação de sono de ambos os grupos (GE e GC).

Os resultados obtidos indicam que não há diferença significante nas médias dos pesos entre o GE e GC em todas as medidas realizadas, mas o GE apresentou média de peso menor do que o GC em todas as medidas realizadas indicando diminuição de peso.

Para as análises cariométricas e estereológicas, foram avaliados apenas cinco animais de cada grupo (Tabelas 2 e 3 ).

As análises cariométricas indicam diferença significante em relação ao diâmetro menor $(\mathrm{p}=0,03)$ e volume $(\mathrm{p}=0,04)$ do núcleo dos hepatócitos, que foram menores nos animais do GE (Tabela 2).
As análises estereológicas indicaram diferença significante entre a densidade de volumes do núcleo $(\mathrm{p}=0,036)$, maior no $\mathrm{GE}$, do citoplasma ( $p=0,009)$, menor no GE e outras estruturas $(p=0,008)$, maior no GE (Tabela 3).

\section{DISCUSSÃO}

Estudos indicam que a privação de sono aumenta o dispêndio de energia e a perda de peso em animais ${ }^{18,19}$. Neste estudo, também houve perda de peso no grupo experimental. É provável que esta perda de peso se deva ao aumento da demanda metabólica para se manter acordado, o que tem relação com as alterações histométricas nucleares e celulares verificadas neste estudo.

Galli et al. ${ }^{20}$ não identificaram hiperfagia entre os grupos experimental e controle, mas houve perda de peso no grupo estudado. Neste estudo, o grupo controle apresentou aumento de peso, possivelmente por hiperfagia, enquanto o grupo experimental teve

Tabela 1: Valores de peso (em gramas) dos animais dos grupos controle e experimental antes, durante e após privação de sono

\begin{tabular}{|c|c|c|c|c|c|}
\hline $\begin{array}{l}\text { Medida } \\
\text { de peso }\end{array}$ & Grupos & $\mathbf{n}$ & Média & Desvio Padrão & Valor $p$ \\
\hline \multirow{2}{*}{$\begin{array}{l}\text { pré } \\
1^{\circ} \text { dia }\end{array}$} & Controle (GC) & 8 & 243,7500 & 8,76275 & \multirow{2}{*}{0,241} \\
\hline & Experimental (GE) & 8 & 241,8750 & 6,51235 & \\
\hline \multirow{2}{*}{$\begin{array}{l}\text { pré } \\
7^{\circ} \mathrm{dia}\end{array}$} & Controle (GC) & 8 & 270,0000 & 14,05093 & \multirow{2}{*}{0,594} \\
\hline & Experimental (GE) & 8 & 275,6750 & 11,67424 & \\
\hline \multirow{2}{*}{$\begin{array}{l}\text { pós } \\
1^{\circ} \mathrm{dia}\end{array}$} & Controle (GC) & 8 & 275,4375 & 16,40217 & \multirow{2}{*}{0,610} \\
\hline & Experimental (GE) & 8 & 264,4375 & 15,23492 & \\
\hline \multirow{2}{*}{$\begin{array}{l}\text { pós } \\
2^{\circ} \text { dia }\end{array}$} & Controle (GC) & 8 & 283,8750 & 13,70023 & \multirow{2}{*}{0,469} \\
\hline & Experimental (GE) & 8 & 265,7375 & 20,07044 & \\
\hline \multirow{2}{*}{$\begin{array}{l}\text { pós } \\
3^{\circ} \mathrm{dia}\end{array}$} & Controle (GC) & 8 & 287,7125 & 16,82867 & \multirow{2}{*}{0,992} \\
\hline & Experimental (GE) & 8 & 261,1875 & 17,68966 & \\
\hline \multirow{2}{*}{$\begin{array}{l}\text { pós } \\
4^{\circ} \mathrm{dia}\end{array}$} & Controle (GC) & 8 & 282,2500 & 16,43602 & 0,401 \\
\hline & Experimental (GE) & 8 & 247,3125 & 18,84512 & \\
\hline
\end{tabular}

$\mathrm{p} \leq 0,05$. Medida de peso pré ( $1^{\circ}$ e $7^{\circ}$ dia): os dois animais se encontram na mesma gaiola. Medida de peso pós $\left(1^{\circ}, 2^{\circ}, 3^{\circ}, 4^{\circ}\right.$ dia): os animais são separados. Os animais do grupo controle permanecem na gaiola inicial e os animais do grupo experimental são colocados no aparato de PSD. Nesta fase, os animais foram pesados todos os dias

Tabela 2: Valores médio do diâmetro maior, menor e da média entre diâmetro maior e menor

\begin{tabular}{|c|c|c|c|c|}
\hline Parâmetros & Experimental & Controle & $\mathbf{U}$ & Valor $\mathrm{p}[\mathrm{U}]$ \\
\hline Diâmetro maior $\mu \mathrm{m}$ & 7,6 & 7,96 & 7,500 & 0,286 \\
\hline Diâmetro menor $\mu \mathrm{m}$ & 6,48 & 7,26 & 2,500 & $0,03^{*}$ \\
\hline Diâmetro médio $\mu \mathrm{m}$ & 7,02 & 7,58 & 3,500 & 0,59 \\
\hline Diâmetro maior/menor & 1,184 & 1,102 & 7,000 & 0,243 \\
\hline Volume $\left(\mu \mathrm{m}^{3}\right)$ & 190 & 234 & 3,000 & $0,04^{*}$ \\
\hline Área $\left(\mu m^{2}\right)$ & 39,2 & 45,8 & 4,000 & 0,075 \\
\hline Perímetro & 22,04 & 23,92 & 4,000 & 0,74 \\
\hline Volume/área & 4,66 & 5,08 & 3,500 & 0,059 \\
\hline Coef forma & 0,982 & 0,996 & 4,500 & 0,08 \\
\hline Índice contorno & 3,572 & 3,552 & 6,000 & 0,126 \\
\hline Excentricidade & 0,462 & 0,372 & 7,500 & 0,292 \\
\hline
\end{tabular}

${ }^{*} \mathrm{p} \leq 0,05=$ significante. Volume $\left(\mu \mathrm{m}^{3}\right)$, área $\left(\mu \mathrm{m}^{2}\right)$, perímetro, média entre volume/área, coeficiente de forma, índice de contorno e excentricidade do fígado. Mann-Whitney test. 
Tabela 3: Média dos valores do núcleo, volume do citoplasma $\left(\mu \mathrm{m}^{3}\right)$ e outras estruturas do fígado

\begin{tabular}{|l|c|c|c|c|}
\hline Parâmetros & Experimental & Controle & $\mathbf{U}$ & $\begin{array}{c}\text { Valor } \\
\mathbf{p}[\mathbf{U}]\end{array}$ \\
\hline Núcleo & 11,86 & 8,92 & 2,500 & $0,036^{*}$ \\
\hline Citoplasma & 82,26 & 88,86 & 0,000 & $0,009^{*}$ \\
\hline Outras estruturas & 5,88 & 2,24 & 0,000 & $0,008^{*}$ \\
\hline
\end{tabular}

${ }^{*} \mathrm{p} \leq 0,05=$ significante. Mann-Whitney test.

perda de peso. Estudo de Moles et al. ${ }^{21}$ indicam que o estresse pode alterar o balanço energético em animais roedores.

O cortisol atua de uma maneira intensa sobre o metabolismo hepático, induzindo alterações metabólicas que podem explicar a diferença morfológica e estrutural entre o hepatócito do grupo experimental e o controle. Um dos principais efeitos do cortisol sobre o metabolismo é a redução dos depósitos proteicos em praticamente todas as células corporais, exceto no fígado. Existe um estado de redução da síntese de proteína e maior catabolismo destas no organismo, e um dos efeitos do cortisol é aumentar o transporte de aminoácidos, elemento fundamental à síntese proteica, para o interior das células hepáticas. Ainda, tal hormônio estimula a ativação da transcrição de DNA nos núcleos dos hepatócitos. Todo esse processo, portanto, leva a um aumento da síntese proteica hepática ${ }^{4}$.

O estudo cariométrico dos hepatócitos dos animais do grupo experimental deste estudo revelou redução estatisticamente significante $(\mathrm{p} \leq 0,05)$ do diâmetro menor e do volume dos núcleos dos hepatócitos sem alteração da forma.

Em relação às medidas estereológicas, verificou-se que a densidade de volume dos núcleos e de outras estruturas dos hepatócitos aumentaram significantemente, enquanto o volume citoplasmático diminuiu $(\mathrm{p} \leq 0,05)$. Tal fato permite a percepção de que há aumento real do número de hepatócitos e de outras estruturas do fígado dos animais do grupo experimental.

Sugere-se que as diferenças morfológicas apresentadas pela célula do grupo experimental, provavelmente se relacionam a um aumento no metabolismo induzido pelos efeitos da corticosterona no organismo, levando a um aumento da degradação proteica em tecidos, o que aumenta a disponibilidade de aminoácidos séricos, que são levados ao fígado. Por outro lado, induz a transcrição de DNA nos núcleos das células hepáticas, levando a um aumento consequente do processo de tradução, o que acarreta um estímulo à produção de proteínas hepáticas.

Ainda, estudos sugerem uma relação altamente significante da privação de sono e o aumento do estresse oxidativo e de danos à fosfolipideos ${ }^{22}$, o que pode levar ao dano de macromoléculas como DNA, RNA e proteínas ${ }^{23}$. A indução de danos oxidativos nas bases do DNA ocorre a partir da sua reação com ROS (espécies reativas de oxigênio). Essas lesões podem ocorrer devido à oxidação direta dos ácidos nucléicos ou, muitas vezes, podem levar à formação de quebras em uma das cadeias do DNA (quebras simples - SSB "single strand break") ou quebras simples em posições aproximadamente simétricas nas duas cadeias do DNA (quebras duplas - DSB “double strand break”). Além disso, quebras simples podem gerar quebras duplas durante a replicação celular ${ }^{24}$. O fígado, também, é um órgão essencial na produção de uma resposta aguda ao estresse, produzindo diversos produtos como proteína C reativa, ceruloplasmina, transferrina e alfa- ${ }_{1}$-antitripsina ${ }^{23}$. O estresse oxidativo pode levar, portanto, a um aumento na produção de proteínas de fase aguda do processo inflamatório, além de ser um potencial agente danoso à atividade gênica da célula hepática.

Assim, as alterações morfométricas do fígado sugerem um efeito deletério do estresse no organismo como um todo, afetando as estruturas no núcleo celular.

\section{AGRADECIMENTOS}

Agradecemos a todos os profissionais que nos auxiliaram para a realização desta pesquisa: Domingos Zanchett Neto; Luiz Onivaldo Bizuti; Prof. Dr. Antonio Carlos Brandão; Prof. Dr. Plínio Luppino; Profa. Dra. Ana Cláudia Polli Lopes; Profa. Dra. Órfã Yineth Galvis Alonso.

\section{REFERÊNCIAS}

1. Lipp MEN, Malagris LEN. Estresse: aspectos históricos, teóricos e clínicos. In: Rangé B (org.). Psicoterapias cognitivocomportamentais: um diálogo com a psiquiatria. Porto Alegre: Artmed; 2011.

2. Greenberg JS. Administração do estresse. $6^{a}$ ed. Barueri: Manole; 2002.

3. Sapolsky RM, Romero LM, Munck AU. How do glucocorticoids influence stress responses? Integranting permissive, suppressive, stimulatory and preparative actions. Endocr Rev. 2000;21(1):55-89.

4. Guyton H. Tratado de fisiologia médica. Elsevier; 2006.

5. Jun J, Polotsky VY. Metabolic consequences of sleep-disordered breathing. ILAR J. 2009;50(3):289-306.

6. Khani S, Tayek JA. Cortisol increases gluconeogenesis in humans: its role in metabolic syndrome. Clin Sci (Lond). 2001;101(6):739-47.
7. Björntörp P. Metabolic difference between visceral fat and subcutaneous abdominal fat. Diabetes Metab. 2000;26(Suppl 3):10-12.

8. Goldstein RE, Wasserman DH, McGuinness OP, Brooks D, Lacy $\mathrm{DB}$, Cherrington AD. Effects of chronic elevation in plasma cortisol on hepatic carbohydrate metabolism. Am J Physiol. 1993;264(1 pt 1): E119-27.

9. Palma BD, Tiba PA, Machado RB, Tufik S, Suchecki D. Repercussões imunológicas dos distúrbios do sono: o eixo hipotálamo-pituitária-adrenal como fator modulador. Rev Bras Psiquiatr. 2007;29(Suppl 1):S33-8.

10. Andersen ML, Martins PJF, D'Almeida V, Bignotto M, Tufik S. Endocrinological and catecholaminergic alterations during sleep deprivation and recovery in male rats. J Sleel Res. 2005;14(1):83-90. 
11. Knustson KL, Spiegel K, Penev $\mathrm{P}$, Van E. The metabolic consequences of sleep deprivation. Sleep Med Ver. 2007;11(3):163-78.

12. De Mattos AB, Pinto MJ, Oliveira C, Biz C, Ribeiro EB, Nascimento $\mathrm{CM}$, et al. Dietary fish oil did not prevent sleep deprived rats from a reduction in adipose tissue adinonectin gene expression. Lipids Health Dis. 2008;7:43

13. Chang HM, Wu UI, Lin TB, Lan CT, Chien WC, Huang WL, et al. Total sleep deprivation inhibits the neuronal nitric oxide synthase and cytochrome oxidase reactivities in the nodose ganglion of adult rats. J Anat. 2006;209(2):239-50.

14. Thase ME. Depression and sleep: pathophysiology and treatment. Dialogues Clin Neurosci. 2006;8(2):217-26.

15. Vgontzas AN, Chrousos GP. Sleep, the hypothalamicpituitary-adrenal axis, and cytokines: multiple interactions and disturbances in sleeo disorders. Endocrinol Metab Clin North Am. 2002;31(1):15-36.

16. Bueno OF, Oliveira MG, Lobo LL, Morais PR, Melo FH, Tufik S. Cholinergic modulation of inhbitory avoidance impairment induced by paradoxical sleep deprivation. Prog Neuropsychopharmacol Biol Psychiatry. 2000;24(4):595-606.

17. Ferraz MR, Ferraz MM, Santos R. How REM sleep deprivation and amantadine affects male rat sexual behavior. Pharmacol Biochem Behav. 2001; 69(3-4):325-32
18. Hipólide DC, Suchecki D, Pimentel de Carvalho Pinto A, Faria EC, Tufik S, Luz J. Paradoxical sleep deprivation and sleel recovery: effects on the hypothalamic-pituitary-adrenal axis activity, energy balance and body composition of rats. J Neuroendocrinol. 2006;18(4):231-38

19. Koban M, Sita LV, Le WW, Hoffman GE. Sleep deprivation of rats the hyperphagic response is real. Sleep. 2008;31(7):972-33.

20. Galli MR, Martins PJF, Souza FG, Azzalis LA, D’Almeida V, Tufik S. Efeitos da privação de sono sobre o metabolismo hepático de ratos. Disponível em http://www.unifesp.br/prograd/pibic2003/ Resumos/25.prn.pdf 2003. Acesso em: 17 jun. 2013.

21. Moles A, Bartolomucci A, Garbugino L, Conti R, Caprioli A, Coccurello R, et al. Psychosocial stress affects energy balance in mice: modulation by social status. Psychoneuroendocrinology. 2006;31(5):623-33

22. Chang HM, Mai FD, Chen BJ, Wu Un-In, Huang YL, Lan CT, et al. Sleep deprivation predisposes liver to oxidative stress and phospholipid damage: a quantitative molecular imaging study. J Anat. 2008;12(3):295-305.

23. Meyer TN, Silva AL. Resposta celular ao estresse. Rev Assoc Med Bras. 1999;45(2):181-8.

24. Berra CM, Menck CFM, Di Mascio P. Estresse oxidativo, lesões no genoma e processos de sinalização no controle do ciclo celular. Rev Quím Nova. 2006;29(6): 1340-4. 